CYBERNETICS AND INFORMATION TECHNOLOGIES • Volume 17, No 5

Special issue with selected papers from the workshop

"Two Years Avitohol: Advanced High Performance Computing Applications 2017"

Sofia $\bullet 2017$

Print ISSN: 1311-9702; Online ISSN: 1314-4081

DOI: $10.1515 /$ cait-2017-0053

\title{
High Performance Computing Simulations of the Atmospheric Composition in Bulgaria and the City of Sofia
}

\author{
Ivelina Georgieva ${ }^{1}$, Georgi Gadzhev ${ }^{1}$, Kostadin Ganev ${ }^{1}$, Dimitrios \\ Melas $^{2}$, Tijian Wang ${ }^{3}$ \\ ${ }^{1}$ National Institute of Geophysics, Geodesy and Geography - Bulgarian Academy of Sciences, 1113 \\ Sofia, Bulgaria \\ ${ }^{2}$ Aristotle University of Thessaloniki Faculty of Sciences School of Physics, 54124 Thessaloniki, Greece \\ ${ }^{3}$ School of Atmospheric Sciences, Nanjing University, Nanjing, China \\ E-mails: iivanova@geophys.bas.bg_ggadjev@geophys.bas.bg_kganev@geophys.bas.bg \\ melas@auth.gr tjwang@nju.edu.cn
}

Abstract: Some extensive numerical simulations of the atmospheric composition fields in Bulgaria and Sofia have been recently performed. The US EPA Model-3 system was chosen as a modeling tool. A very extensive database was created from simulations which was used for different studies of the atmospheric composition, including the Air Quality (AQ) climate.

Keywords: High Performance Computing (HPC), simulations, atmospheric composition, air pollutants.

\section{Introduction}

The atmospheric composition studies were based on extensive computer simulations carried out with good resolution using up-to-date modelling tools and detailed and reliable input data. All the simulations were based on the US EPA (Environmental Protection Agency) Model-3 system, which consists of three models: WRF (Weather Research and Forecasting) used as meteorological pre-processor; CMAQ - the Community Multiscale Air Quality System, being the Chemical Transport Model (CTM); SMOKE (Sparse Matrix Operator Kernel Emissions) Modelling System-the emission pre-processor. The simulations were performed for 7-year period (20082014) with Two-Way Nesting mod on. Carrying out reliable, comprehensive and detailed studies of the influence of the parameters and characteristics of lower atmosphere requires various types of data such as meteorological and chemical fields and measurements - Air Quality (AQ) data, emission inventories and physiographic data. The data is necessary as an input to the respective studies, as well as for evaluation and validation of the modelling approaches and tools [1-5]. 
A very extensive database was created from the numerical simulations and this data was used for different studies of the atmospheric composition, including the AQ climate. The air pollution pattern is formed as a result of interaction of different processes, so knowing the contribution of each one of these processes for different meteorological conditions and given emission spatial configuration and temporal behaviour could be helpful for understanding the atmospheric composition and air pollutants behaviour. Therefore the CMAQ "Integrated Process Rate Analysis" option was applied to discriminate the role of different dynamic and chemical processes for the air pollution formation. Different characteristics of the numerically obtained concentration fields, as well as evaluating the impact of air pollutants on quality of life in the term of AQI and of the contribution of different processes will be demonstrated in the present paper.

\section{Methodology}

The simulations were performed using the US EPA models three system.

Meteorological model WRF [6]. The Weather Research and Forecasting (WRF) model is a Numerical Weather Prediction (NWP) and atmospheric simulation system designed for both research and operational applications. It supplies various dispersion models, including presented below model CMAQ with input meteorological fields. WRF is suitable for a broad span of applications across scales ranging from large-eddy to global simulations.

Meteorological data. The large-scale (background) meteorological fields, used by the application were taken from the NCEP Global Analysis Data with $1^{\circ} \times 1^{\circ}$ resolution. The WRF and CMAQ nesting capabilities were used to downscale the simulations to a $9 \mathrm{~km}$ for domain D3 - Bulgaria, and to a $1 \mathrm{~km}$ horizontal resolution for the innermost domain - Sofia. The simulations were carried out for five nested domains (Fig. 1).

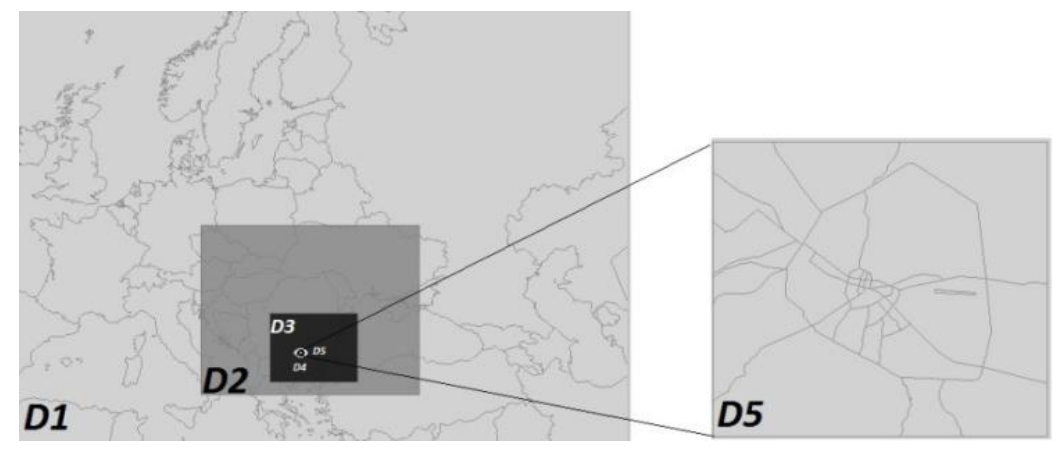

Fig. 1. Model domains: D1 81×81 km (Europe); D2 27×27 km (Balkan Peninsula); D3 $9 \times 9$ km (Bulgaria); D4 3×3 km (Sofia municipality); D5 1×1 km (Sofia city)

Emission model SMOKE [7]. The Sparse Matrix Operator Kernel Emissions (SMOKE) was designed to integrate the emission data using sparse-matrix algorithms. SMOKE was created to allow emissions data for the AQ model's needs. 
SMOKE provides a mechanism for preparing specialized inputs for AQ modelling research, and it makes AQ forecasting possible. SMOKE can process criteria gaseous pollutants and has no limitation regarding the number or types of pollutants it can process. The purpose of SMOKE is to convert the resolution of the emission inventory data to the resolution needed by an AQ model.

Emission data. The Bulgarian emission inventory was used as an emission input for Bulgaria. Special pre-processing procedures were created for introducing temporal profiles and speciation of the emissions. GIS (Geographic Information System) technology is applied as to produce area and large point source input from this data base. Outside the country the TNO (Netherlands Organisation for Applied Scientific Research) high resolution inventory was exploited $0.25^{\circ} \times 0.125^{\circ}$ (about $20 \times 15 \mathrm{~km}$ ) and the emissions were distributed over 10 SNAPs category [8]. The inventory is produced by proper disaggregation of the EMEP 50-km inventory data base $[9,10]$. Currently, SMOKE supports Area, Mobile and Point Sources emissions processing and also includes biogenic emissions modelling through both a rewrite of the Biogenic Emission Inventory System (BEIS3) [11].

The Atmosphere Composition Model CMAQ [12-14]. The Community Multiscale Air Quality (CMAQ) modelling system is a tool for transport and chemical transformations of pollutants in the atmosphere and it is a part of US EPA Models-3 System. CMAQ as part of the system used meteorological data prepared by the model WRF and emission data, prepared by the model SMOKE. CMAQ is Eulerian model, "one atmosphere", which takes into account interactions between pollutants (about 100 species) in various dynamic scales. The model handles complex compositions of pollutants and configuration of sources, modelled transport and diffusion in a dynamic environment in wide time range - from minutes to days and weeks, and in the corresponding spatial scales - from local to global.

\section{Grid computing}

As it was stated above the WRF/CMAQ simulations were performed day by day for 7-year period. Thus a very extensive database was created, which could be used for different studies and considerations of the main features and origins of the atmospheric composition in different scales, including the AQ climate. The computer resource requirements for the model (WRF, SMOKE and CMAQ) simulations are rather big [15] (Tables 1 and 2) and that is why the numerical experiments were organized in effective HPC environment. The simulations were organized in two separate jobs: one job for WRF simulations and one for SMOKE, CMAQ and postprocessing procedures. This makes the jobs run time for 6 days real time fairly reasonable. The calculations were implemented on the Supercomputer System Avitohol at IICT-BAS (Institute of Information and Communication TechnologiesBulgarian Academy of Sciences). This supercomputer consists of $150 \mathrm{HP}$ Cluster Platform SL250S GEN8 servers, each one equipped with two Intel Xeon E5-2650 V2 8C $2600 \mathrm{GHz}$ CPUs and 64GB RAM per server. The storage system is HP MSA 2040 SAN with a total of 96 TB of raw disk storage capacity. All the servers are interconnected with fully non-blocking FDR Infiniband, using a fat-tree topology. 
Table 1. Computer resource requirements for models

\begin{tabular}{|c|c|c|c|}
\hline \multirow{2}{*}{ Time/HDD } & \multicolumn{3}{|c|}{ 1 Day simulation at 16 CPU } \\
\cline { 2 - 4 } & WRF & CMAQ and SMOKE & Total \\
\hline Time & $3 \mathrm{~h}$ & $2 \mathrm{~h}$ & $5 \mathrm{~h}$ \\
\hline HDD & $530 \mathrm{MB}$ & $970 \mathrm{MB}$ & $1.5 \mathrm{~GB}$ \\
\hline
\end{tabular}

Table 2. Computer resource requirements for CMAQ model

\begin{tabular}{|l|l|l|l|l|l|l|}
\hline Time & CPU/HDD & D2/27 km & D $3 / 9 \mathrm{~km}$ & D4/3 km & D5/1 km & Total \\
\cline { 2 - 7 } & $2 \mathrm{CPU}(\mathrm{min})$ & $2 \mathrm{~h} 40 \mathrm{~min}$ & $1 \mathrm{~h} 10 \mathrm{~min}$ & $1 \mathrm{~h} 36 \mathrm{~min}$ & $32 \mathrm{~min}$ & $5 \mathrm{~h} 58 \mathrm{~min}$ \\
\cline { 2 - 7 } & $4 \mathrm{CPU}(\mathrm{min})$ & $1 \mathrm{~h} 20 \mathrm{~min}$ & $35 \mathrm{~min}$ & $30 \mathrm{~min}$ & $10 \mathrm{~min}$ & $2 \mathrm{~h} 35 \mathrm{~min}$ \\
\cline { 2 - 8 } & $8 \mathrm{CPU}(\mathrm{min})$ & $20 \mathrm{~min}$ & $20 \mathrm{~min}$ & $17 \mathrm{~min}$ & $6 \mathrm{~min}$ & $63 \mathrm{~min}$ \\
\cline { 2 - 7 } & $16 \mathrm{CPU}(\mathrm{min})$ & $30 \mathrm{~min}$ & $20 \mathrm{~min}$ & $12 \mathrm{~min}$ & $5 \mathrm{~min}$ & $67 \mathrm{~min}$ \\
\hline 1 day & $\mathrm{HDD}(\mathrm{MB})$ & $255 \mathrm{MB}$ & $420 \mathrm{MB}$ & $70 \mathrm{MB}$ & $145 \mathrm{MB}$ & $890 \mathrm{MB}$ \\
\hline 7 years & $\mathrm{HDD}(\mathrm{GB})$ & $636 \mathrm{MB}$ & $1048 \mathrm{MB}$ & $175 \mathrm{MB}$ & $362 \mathrm{MB}$ & $2221 \mathrm{MB}$ \\
\hline
\end{tabular}

The model output storage, however, is too large. Not all the information from the model output is so valuable for further air quality and environmental considerations, so an additional post-processing procedure and respective software (the program XTRACT) were developed, to reduce the information (only the necessary information to be kept) and the needed storage space. This procedure allows not only the number of output compounds to be reduced but also the number of the vertical levels. Another post-processing procedure was applied for statistical treatment of the results to present different statistical characteristics as the mean, minimum and maximum concentrations, probability density, bias, errors and etc., not only for the whole domain but also for selected points of interest. What are recently kept from the CMAQ output on an hourly basis are the surface concentrations of the following most important pollutants:

- 34 gases - $\mathrm{NO}_{2}, \mathrm{NO}, \mathrm{O}_{3}, \mathrm{NO}_{3}, \mathrm{OH}, \mathrm{HO}_{2}, \mathrm{~N}_{2} \mathrm{O}_{5}, \mathrm{HNO}_{3}, \mathrm{HONO}, \mathrm{PNA}, \mathrm{H}_{2} \mathrm{O}_{2}$, CO, FORM, ALD ${ }_{2}, \mathrm{C}_{2} \mathrm{O}_{3}$, PAN, PACD, PAR, OLE, FACD, AACD, ETH, TOL, CRES, TO2, XYL, MGLY, ISOP, ISPD, $\mathrm{SO}_{2}, \mathrm{SULF}\left(\mathrm{H}_{2} \mathrm{SO}_{4}\right)$, UMHP, TERP, $\mathrm{NH}_{3}$;

- 5 aerosols - $\mathrm{PSO}_{4}, \mathrm{PNH}_{4}, \mathrm{PNO}_{3}, \mathrm{POA}, \mathrm{PEC}$;

- 2 Anthropogenic and Biogenic secondary organic aerosols - SOAA, SOAB;

- 2 fine and coarse PM - FPRM, CPRM.

A key factor in the present work is the appropriate choice of metrics, which evaluate the impact of air environment on quality of life and human health, respectively elaboration of software, which to calculate the introduced metrics on the basis of the atmospheric composition. An integral characteristic, which reflects the impact of the atmospheric composition on general population health and quality of life will be presented in this paper - the Air Quality Index (AQI). 


\section{Results}

As mentioned above, a very extensive database was created from the numerical simulations and this data was used for different studies of the atmospheric composition, including the AQ climate.

The most simple and natural atmospheric composition evaluations are the surface concentrations, so by averaging over the whole simulated fields' ensemble the mean annual and seasonal surface concentrations can be obtained and treated like "typical" daily concentration patterns. The simulated ensemble is large enough to allow different statistical treatment. The probability density functions for each of the atmospheric compounds can be calculated for each grid point, or averaged over a chosen territory, with the respective seasonal and diurnal variations. Knowing the probability density functions means to know everything about the ensemble.

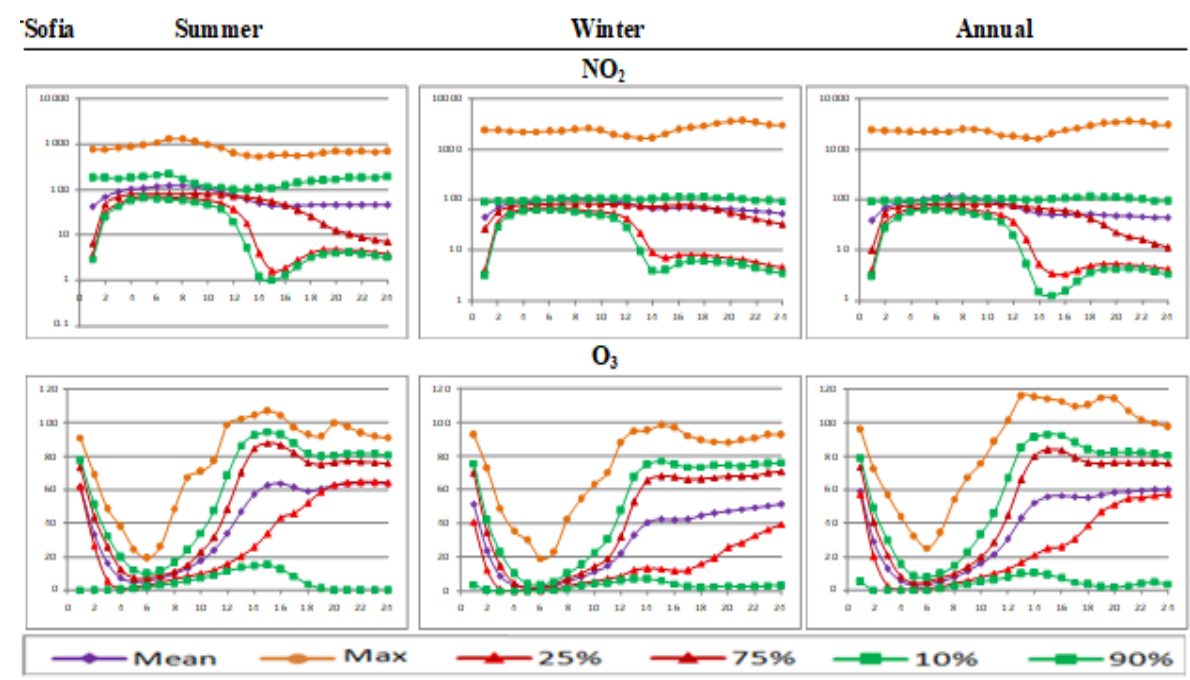

Fig. 2. Seasonal and diurnal variations of the "typical" surface concentrations for $\mathrm{NO}_{2}$ and $\mathrm{O}_{3}$, averaged for the territory of the city of Sofia

In Fig. 2 the seasonal and diurnal variations of the "typical" surface concentrations for $\mathrm{NO}_{2}$ and $\mathrm{O}_{3}$, averaged for the territory of the city of Sofia are presented. The curves in the graphics present the diurnal course of mean and maximal concentrations. The curves denoted by $25,75,10$ and $90 \%$ show the imaginary concentrations for which the probability of the simulated ones to be smaller respectively than 25 th, 75 th, 10 th and 90th percentiles of all. Thus the band 25-75 contains $50 \%$ and the band $10-90$ contains $80 \%$ of the possible cases.

The diurnal variations of surface concentration fields are very well manifested.

Calculation of the Air Quality (AQ) impact on human health and quality of life. The AQ impact on human health and quality of life is an issue of great social significance. Evaluating this impact will give scientifically robust basis for elaborating efficient short term measures and long term strategies for mitigation of the harmful effects of air pollution on human health and quality of life. The AQ 
impact on human health and quality of life is evaluated in the terms of AQ Indices (AQI), which give an integrated assessment of the impact of pollutants and directly measuring the effects of AQ on human health. In the current study the AQI evaluations are based on extensive computer simulations of the AQ for Bulgaria and Sofia city carried out with good resolution using up-to-date modelling tools and detailed and reliable input data [16-19], which makes it possible to revile the climate of AQI spatial/temporal distribution and behaviour on the basis of air pollutant concentrations obtained from the numerical modelling. The index is defined in several segments, each of which is a linear function of the concentration of each pollutant considered: [20]. In that calculation the index falls in the ranges of a dimensionless scale. In each range index values are associated with an intuitive colour code, a linguistic description and a health description.

In different countries the indices are different and have their different scales. In Bulgaria the index, calculated in the frame of Bulgarian Chemical Weather Forecast System [21-23] and follows the UK Daily Air Quality Index [24]. This index has ten grades, which are further grouped into four bands: low, moderate, high and very high (Fig. 3). The index is based on the concentrations of five pollutants - Ozone, Nitrogen Dioxide, Sulphur Dioxide, Carbon Oxide and PM10. The breakpoints between index values are defined for each pollutant separately and the overall index is defined as the maximum value of the index.

\begin{tabular}{|l|l|l|}
\hline \multicolumn{1}{|c|}{ Banding } & Value & \multicolumn{1}{c|}{ Health Descriptor } \\
\hline Low & $1-3$ & $\begin{array}{l}\text { Effects are unlikely to be noticed even by individuals who know they } \\
\text { are sensitive to air pollutants }\end{array}$ \\
\hline Moderate & $4-6$ & $\begin{array}{l}\text { Mild effects, unlikely to require action, may be noticed amongst } \\
\text { sensitive individuals. }\end{array}$ \\
\hline High & $7-9$ & $\begin{array}{l}\text { Significant effects may be noticed by sensitive individuals and } \\
\text { action to avoid or reduce these effects may be needed (e.g. reducing } \\
\text { exposure by spending less time in polluted areas outdoors). } \\
\text { Asthmatics will find that their 'reliever' inhaler is likely to reverse the } \\
\text { effects on the lung. }\end{array}$ \\
\hline Very High & 10 & $\begin{array}{l}\text { The effects on sensitive individuals described for 'High' levels of } \\
\text { pollution may worsen. }\end{array}$ \\
\hline
\end{tabular}

Fig. 3. Air pollution bandings and Index impact on human health

Different averaging periods are used for different pollutants. The reference levels and Health Descriptor used in the tables are based on the health-protection related limit, target or guideline values set by the European regulations, at national or local level or by the World Health Organisation [25, 26].

Annually and seasonally averaged hourly values of the AQI for both domains with different horizontal grid resolution are presented in Fig. 4. The graphs represent the daily and seasonal percent recurrence of the AQI (1-10) over territory of Bulgaria and Sofia. These results, allow to follow which one of the indices has the highest recurrence through the day and during the seasons, and to analyze what are the possible reasons for high values of the index in High and Very High bands meteorological conditions, dominant pollutants, and etc. Such a representation of the index makes it possible to evaluate the atmospheric composition in the context of impacts on human health and quality of life. 


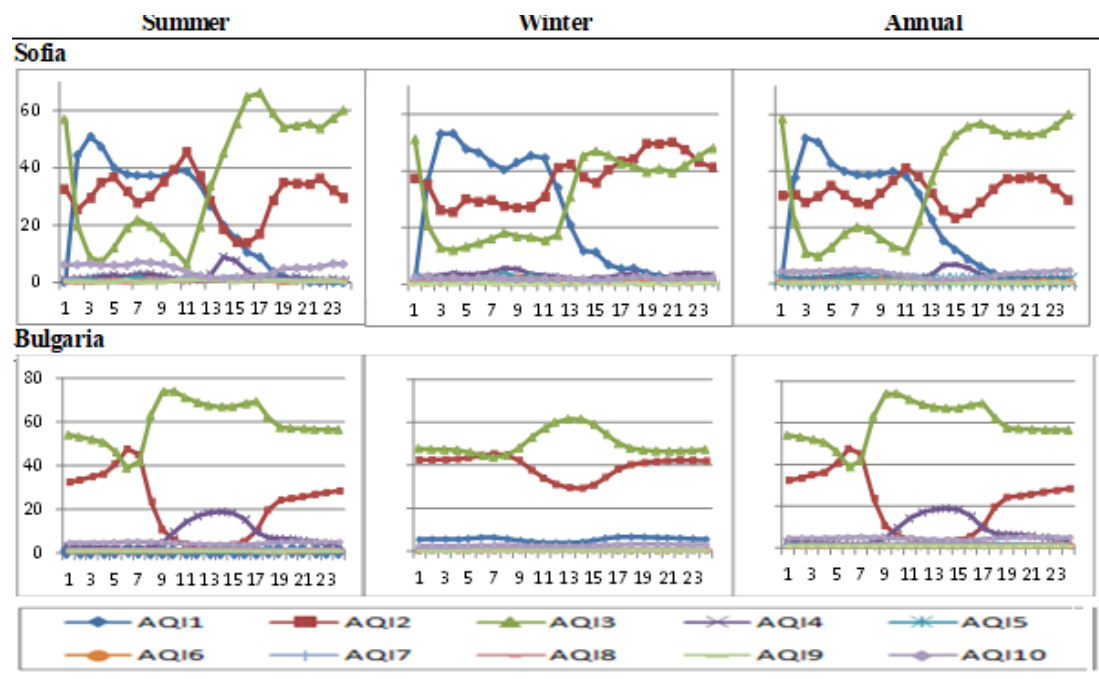

Fig. 4. Diurnal and seasonal variations (\%) of the different AQI (1-10) integrated over territory of Bulgaria and Sofia

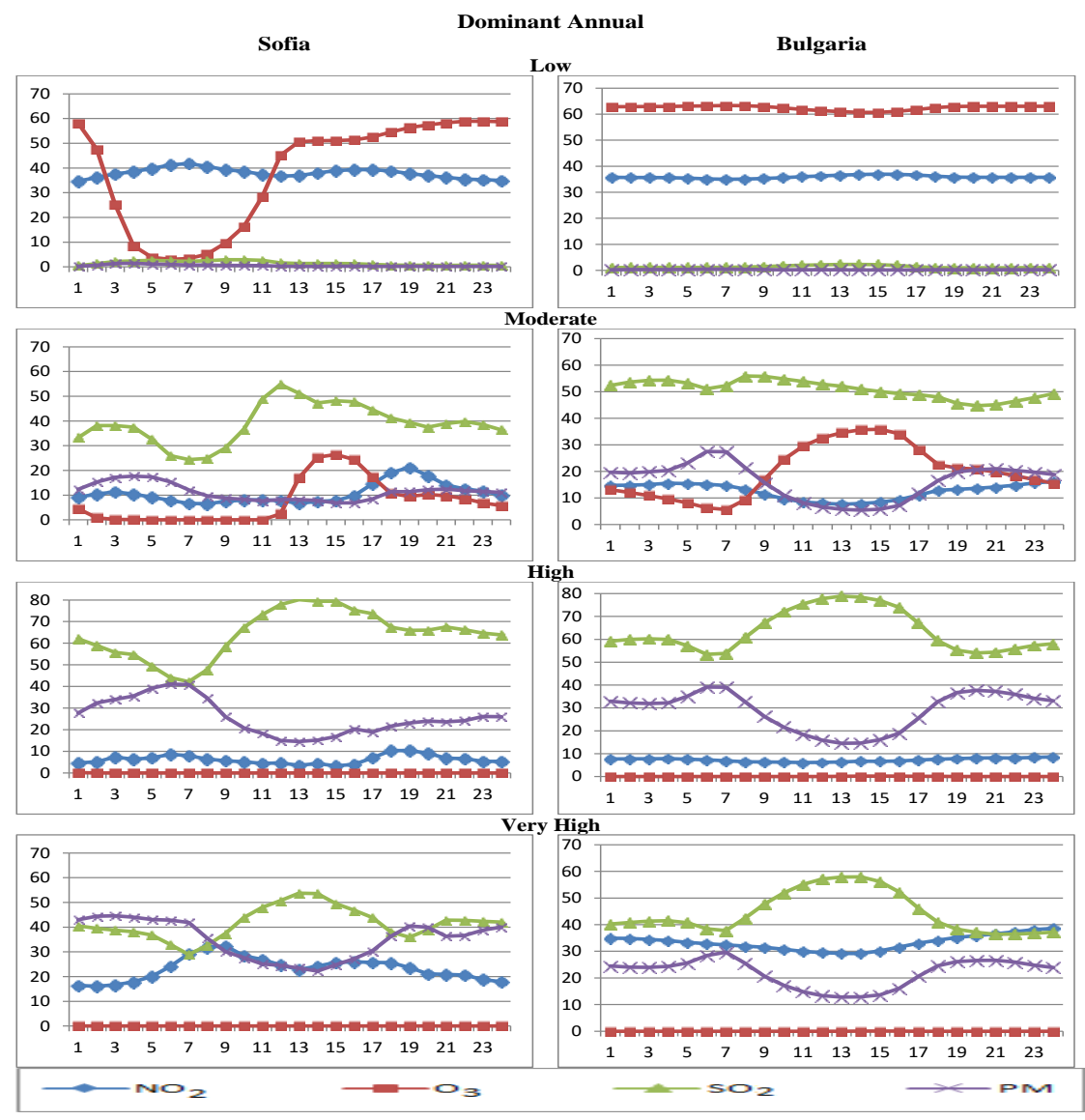

Fig. 5. Annual diurnal variations (\%) of the dominant pollutant 
The graphics that demonstrate the annual recurrence of the dominant pollutant (the pollutant with highest AQI, which determines the overall $\mathrm{AQI}$ ) are presented in Fig. 5 for the four bands. The considered pollutants $-\mathrm{NO}_{2}, \mathrm{O}_{3}, \mathrm{SO}_{2}$ and $\mathrm{PM}$ are presented in different colours. Of course the seasonal cases differ from the annually averaged graphics and the dominant pollutants are different for different band with well displayed seasonal and diurnal course.

Determining the contribution of different types of pollution sources to the AQ of the city of Sofia. The used emission inventory is made for a 10 emission categories (SNAP - Selected Nomenclature for sources of Air Pollution) and allows the evaluation of the contribution of various anthropogenic activities to the overall picture of air pollution:

1. SNAP 1 (Combustion in energy).

2. SNAP 2 (Non-industrial combustion plants).

3. SNAP 3 (Combustion in manufacturing industry).

4. Production processes.

5. Extraction and distribution of fossil fuels.

6. Solvent and other product use.

7. SNAP 7 (Road transport).

8. Other mobile sources and machinery.

9. Waste treatment and disposal.

10. Agriculture.

Six emission scenarios will be considered in the present paper: Simulations with all the emissions, with the emissions of SNAP categories 1 (energetic), 2 (nonindustrial combustions), 3(industrial combustions) and 7 (road transport), and all the emissions for Sofia reduced by a factor of 0.8 . This makes it possible to evaluate the contribution of road transport, energetic, industrial and non-industrial combustions to the atmospheric composition in the city. The concentrations for each scenario of reduced SNAP's were also calculated for each day of this 7-year period. The relative contribution of the emissions for each of the scenarios are calculated in the following way:

Let an arbitrary (concentration, deposition, columnar value, process contribution, etc.) pollution characteristic, for a given grid point, or averaged over chosen domain, obtained with all the emissions accounted for is denoted by $\varphi$. Let $\varphi_{m}$ is the respective characteristic obtained when the emissions form source category $m$ are reduced by a factor of $\alpha$. In such a case the quantity

$$
\phi_{m}=\frac{1}{1-\alpha} \cdot \frac{\varphi-\varphi_{m}}{\varphi} \cdot 100,
$$

can be interpreted as the relative (in \%) contributions of emission category $m$ to the formation of the characteristic $\varphi$. It is obvious that more than one Selected Nomenclature for sources of Air Pollution (SNAP) category emissions can be reduced by a factor of $\alpha$ and so the joint contribution of several or all SNAP categories to the formation of the pollution characteristic $\varphi$ can be evaluated.

Thus obtained relative source contributions can also be averaged for the whole ensemble, thus providing the "climate" of the emission contributions, in particular the "typical" annual and seasonal contributions. 
For all the emission categories the pattern of the contribution fields is rather complex, which reflects the emission source configuration, the heterogeneity of topography, land use and meteorological conditions. Plots of this kind can give a good qualitative impression of the spatial complexity of the emission contribution. In order to demonstrate the emission contribution behavior in a more simple and easy to comprehend way, the respective fields can be averaged over some domain, which makes it possible to follow and compare the diurnal behavior of the respective contributions of different species.

Graphics of the diurnal evolution of the "typical" annual and seasonal relative contributions of the emissions from the already mentioned SNAP categories to the surface concentrations of $\mathrm{NO}_{2}$, FPRM (Fine PaRticulate Matter) and CPRM (Coarse PaRticulate Matter) for the territory of Sofia city are shown in Fig. 6. The relative contributions for the territory of Sofia have well displayed diurnal and seasonal course.

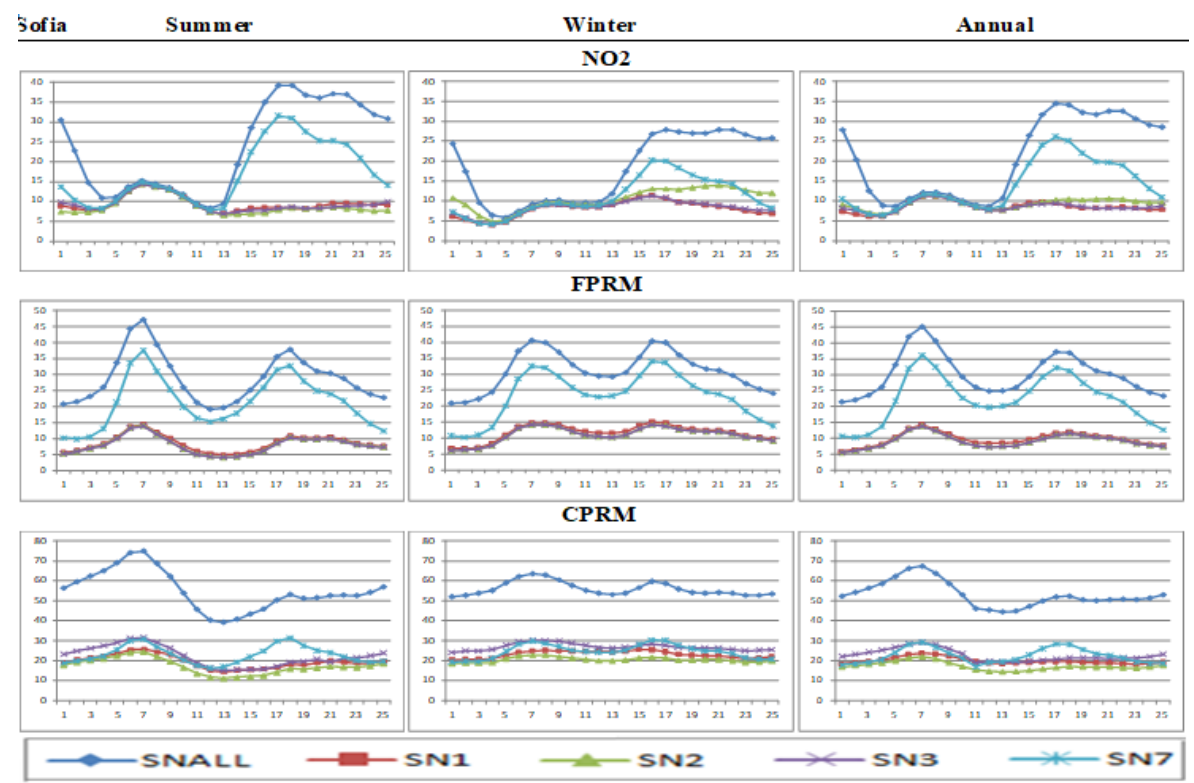

Fig. 6. Annually and seasonal averaged contribution of different SNAP categories (\%) to the formation of $\mathrm{NO}_{2}, \mathrm{FPRM}$ and CPRM for the territory of Sofia city

Determining the contribution of different processes to the surface concentration of pollutants. The Models-3 "Integrated Process Rate Analysis" option was applied to discriminate the role of different dynamic and chemical processes for the air pollution pattern formation. The procedure allows the concentration change for each compound for an hour $\Delta C$ to be presented as a sum of the contribution of the processes, which determine the concentration:

$$
\Delta C=\sum_{i=1}^{N} \Delta c_{i}
$$

The outputs from the Integrated Process Rate Analysis were averaged over the 7-year ensemble and so the "typical" seasonal and annual evaluations were obtained. 
An example of the diurnal/seasonal behavior of some of the processes contributing to the surface concentrations of the pollutant $\mathrm{NO}_{2}$, FPRM and CPRM, averaged for the city of Sofia, is given in Fig. 7. The processes that were considered are: advection, diffusion, mass adjustment, emissions, dry deposition, chemistry, aerosol processes and cloud processes/aqueous chemistry.

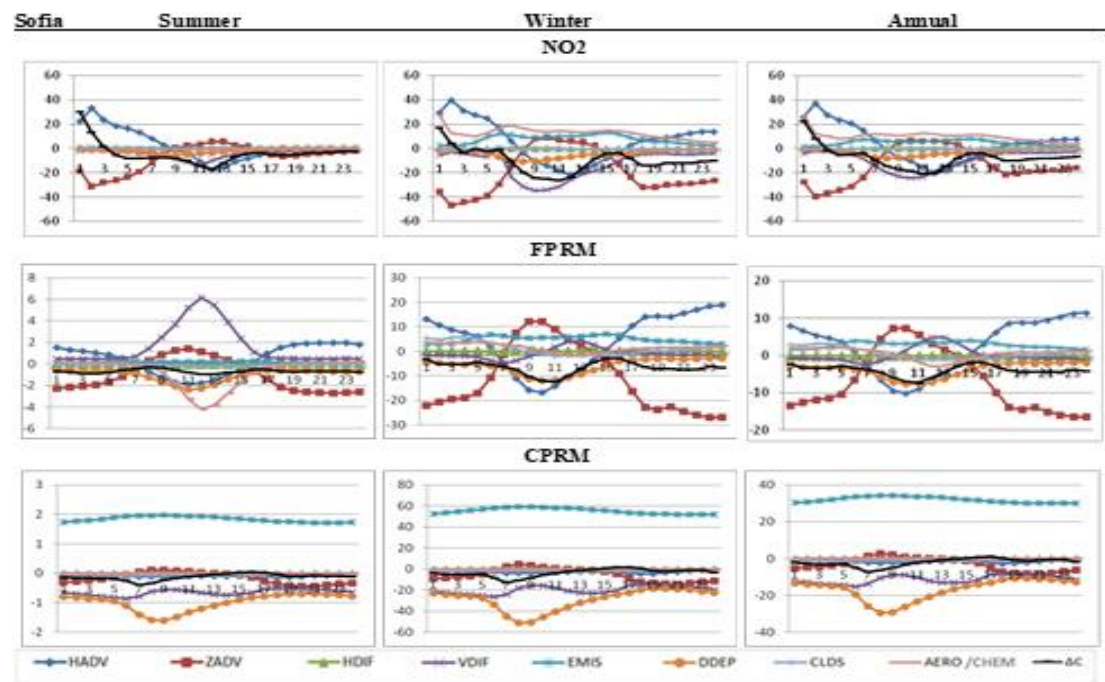

Fig. 7. Annually and seasonal averaged contribution of the different processes to the formation of $\mathrm{NO}_{2}$, FPRM and CPRM $\left(\mu \mathrm{g} / \mathrm{m}^{3}\right.$ per $\left.1 \mathrm{~h}\right)$ for Sofia city

For the whole domain Sofia city, and for each of the selected items, the total concentration change $(\Delta C)$, leading to a change in a concentration is determined mainly by a small number of dominating processes which have large values, and could be with opposite sign and phases. The total concentration change $(\Delta C)$ is different for each pollutant and during the seasons. The sign of the contributions of some of the processes is obvious, but some of them may have different sign depending on the type of emissions, as well as weather conditions and topography.

\section{Conclusion}

A very small part of the obtained results is presented in the present paper, just to demonstrate the opportunity HPC platforms give for detailed and extensive study of the atmospheric composition - its behaviour, origin and health impact. Due to volume limitations the spatial variability of the air pollution characteristics is not demonstrated at all.

The generated ensembles of atmospheric composition characteristics have still to be carefully and extensively treated and analysed, which will be objective of the future work of the authors.

Deep gratitude is due to US EPA and US NCEP, EMEP and to the Netherlands Organization for Applied Scientific research (TNO) for providing free-of-charge data and software and the high-resolution European anthropogenic emission inventory. 
Acknowledgements: The present work is supported by the Bulgarian National Science Fund (Grant ДЦВП-02/1/29.12.2009), ЕС-H2020 Project 675121(Project VI-SEEM), EC-7PП Grant PIRSES-GA2013-612671 (Project REQUA), EC-7PП Grant 261323 (Project EGI-INSPIRE), Program for Career Development of Young Scientists, BAS.

\section{References}

1. K o p a n a k i s, I., et al. Variability of Ozone in the Eastern Mediterranean During a 7-Year Study. - Air. Qual. Atmos. Health, Vol. 9, 2015, pp. 461-470.

2. Kan a kidou, M., et al. Megacities as Hot Spots of Air Pollution in the East Mediterranean. Atmospheric Environement, 2010.

3. L e 1 i e v e 1 d, J., et al. Global air Pollution Crossroads over the Mediterranean. - Science, Vol. 298, 2002, pp. 794-799.

4. Poupkou, A., et al. Effects of Anthropogenic Emission Sources on Maximum Ozone Concentrations over Greece. - Atmospheric Research, Vol. 89, 2008, pp. 374-381.

5. M a r é c a 1, V., et al. A Regional Air Quality Forecasting System over Europe: The MACC-II Daily Ensemble Production. - Geosci. Model Dev., Vol. 8, 2015, pp. 2777-2813.

6. Sh a marock, W., J. K le mp, J. D u dhi a, D. Gill, D. B arker, W. W a n g, J. Powers. A Description of the Advanced Research WRF. Version 2. 2007. http://www.mmm.ucar.edu/wrf/users/docs/arw_v2.pdf

7. CEP Sparse Matrix Operator Kernel Emission (SMOKE) Modeling System. University of Carolina, Carolina Environmental Programs, Research Triangle Park, North Carolina, 2003.

8. V i s s chedij k, A., P. Z a n d ve ld, H. V a n d e r G o n. A High Resolution Gridded European Emission Database for the EU Integrated Project GEMS. TNO Report 2007-A-R0233/B, The Netherlands Brunekreef B, Holgate S: Air Pollution and Health. - Lancet 2002, Vol. 360, 2007, pp. 1233-1242.

9. V e s t r e n g, V. Emission Data Reported to UNECE/EMEP: Evaluation of the Spatial Distribution of Emissions. Meteorological Synthesizing Centre - West, The Norwegian Meteorological Institute, Oslo, Norway, Research Note 56, EMEP/MSC-W Note 1/2001, 2001.

10. Vestreng, V., K. B re ivik, M. Ad a m s, A. W a gne r, J. Goodwin, O. Rozovskaya, J. M. P a c y n a. Inventory Review 2005, Emission Data reported to LRTAP Convention and NEC Directive, Technical Report MSC-W 1/2005, EMEP, 2005.

11. S c h w e d e, D., G. P o u 1 i o t, T. P i e r c e. Changes to the Biogenic Emissions Invenory System Version 3 (BEIS3). - In: Proc. of 4th Annual CMAS Models-3 Users's Conference, 26-28 September 2005, Chapel Hill, NC.

12. B y u n, D., et al. Description of the Models-3 Community Multiscale Air Quality (CMAQ) Modeling System. - In: Proc. of 10th Joint Conference on the Applications of Air Pollution Meteorology with the A\&WMA, 11-16 January 1998, Phoenix, Arizona, pp. 264-268.

13. B y u n, D., J. Ch in g. Science Algorithms of the EPA Models-3 Community Multiscale Air Quality (CMAQ) Modeling System. EPA Report 600/R-99/030, Washington, DC, 1999. http://www.epa.gov/asmdnerl/models3/doc/science/science.html

14. CMAQ User Guide. 2006. https://www.cmascenter.org/help/documentation.cfm?model=cmaq \&version=4.6

15. T o d o r o v a, A., et al. Grid Computing for Atmospheric Composition Studies in Bulgaria. - Earth Science Informatics, Vol. 3, 2010, No 4, pp. 259-282.

16. G a d z h e v, G., K. G a n e v, N. M i l o s h e v, D. S y r a k o v, M. Prod a n o v a. Numerical Study of the Atmospheric Composition in Bulgaria. - Computers and Mathematics with Applications, Vol. 65, 2013, pp. 402-422.

17. G a d z h e v, G., K. G a n e v, M. Prod a nova, D. S y r a k o v, E. A t a n a s o v, N. Milo sh e v. Multi-Scale Atmospheric Composition Modelling for Bulgaria. - NATO Science for Peace and Security Series C: Environmental Security, Vol. 137, 2013, pp. 381-385.

18. G a d z h e v, G., K. G a n e v, N. Mil o s h e v, D. S yrakov, M. Prod an ov a. Analysis of the Processes which Form the Air Pollution Pattern over Bulgaria. - In: I. Lirkov et al., Eds. LSSC 2013. LNCS 8353. Berlin, Heidelberg, Springer-Verlag, 2014, pp. 390-396. 
19. Gadzhev, G., K. Gan ev, N. Miloshev, D. S y rakov, M. Prod a n o va. Some Basic Facts About the Atmospheric Composition in Bulgaria - Grid Computing Simulations. - In: I. Lirkov et al., Eds. LSSC 2013, LNCS 8353, C Springer-Verlag Berlin Heidelberg, 2014, pp. 484-490.

20. EPA. Technical Assistance Document for the Reporting of Daily Air Quality - the Air Quality Index (AQI). EPA-454/B-09-001, US Environmental Protection Agency, Research Triangle Park, North Carolina, Office of Air Quality Planning and Standards, Research Triangle Park, North Carolina 27711, 2009.

21. S yrakov, D., I. Etrop ols k a, M. Prod an ova, K. G a n ev, N. Miloshev, K. S lavov. Operational Pollution Forecast for the Region of Bulgaria. - American Institute of Physics, Conf. Proc. 1487, 2012, pp. 88-94.

22. S yrakov, D., I. Etropolska, M. Prod an ova, K. S l avov, K. G a n ev, N. Miloshev, T. L j u b e n o v. Downscaling of Bulgarian Chemical Weather Forecast from Bulgaria Region to Sofia City. American Institute of Physics, Conf. Proc. 1561, 2013, pp. 120-132.

23. S yrakov, D., M. Prod an ova, I. Etropols k a, K. S l a vov, K. G a n e v, N. Miloshev, T. L j u be n o v. A Multy-Domain Operational Chemical Weather Forecast System. - In: I. Lirkov et al., Eds. LSSC 2013. LNCS 8353. Berlin, Heidelberg, Springer-Verlag, 2014, pp. 413-420,

24. Le e u w, F. De, W. Mol. Air Quality and Air Quality Indices: A World Apart. ETC/ACC Technical Paper 2005/5, 2005. http://acm.eionet.europa.eu/docs/ETCACC_TechnPaper_2005_5_AQ_Indices.pdf

25. Fact Sheet Number 187, World Health Organization (WHO), 2000.

26. Health Aspects of Air Pollution. Results from the WHO Project Systematic Review of Health Aspects of Air Pollution in Europe, World Health Organization (WHO), 2004. 